\title{
Corporate real estate strategy: a conceptual overview
}

\begin{abstract}
This paper is a review of key issues that have emerged in the development of corporate real estate (CRE) over the past two decades and in particular considers how real estate asset holdings and activities support business objectives. The themes explored include definitions of CRE; the roles, contributions and functions of CRE; the paradigm shift in real estate from being a space provider to a strategic resource; and the strategic management context and strategy formulation.
\end{abstract}

Keyword: Corporate real estate; Strategic resource; Paradigm shift 